\title{
Actualización en crup viral para médicos de atención primaria
}

\section{Update in viral croup for primary care physicians}

Pág. 2,11

Recibido: $16-04-2020$

Aceptado: 03-05-2020

Dra. Carolina Mejía Arens. Médico General, Área de Salud Zapote Catedral, Costa Rica.

Dra. Nathalia Sandí Ovares. Médico General, Hospital México, Costa Rica.

Dra. Natalia Salazar Campos. Médico General, Área de Salud Coronado, Costa Rica.

\section{Resumen}

E crup es una enfermedad obstructiva de la vía aérea superior frecuente en niños con edades comprendidas entre los seis meses y los tres años, su principal agente etiológico es el virus Parainfluenza tipo 1. Se caracteriza por presentar la tríada: estridor inspiratorio, disfonía y tos perruna, precedido de un pródromo catarral con o sin fiebre. El diagnóstico es clínico y no requiere realizar exámenes complementarios, si no se sospechan complicaciones graves. La consulta y manejo inicial, usualmente corresponde a los médicos de atención primaria, que deben evaluar y estabilizar la vía aérea según la necesidad, e iniciar el tratamiento dependiendo del grado de severidad.

Palabras Clave: crup, diagnóstico diferencial, estado de gravedad del paciente, terapias.

\section{Abstract}

Croup is a very frequent obstructive disease of the upper airway that presents in children aged between 6 months and 3 years, whose main etiologic agent is type 1 parainfluenza virus. It is characterized by presenting the triad: inspiratory stridor, dysphonia and barking cough, preceded by a catarrhal prodrome with or without fever. The diagnosis is clinical, and does not require complementary tests, if serious complications are not suspected. Its initial management usually corresponds to primary care physicians, who must evaluate and stabilize the airway according to need, and start treatment depending on the degree of severity.

Key words: croup, differential diagnosis, patient acuity, therapies.

\section{Introducción}

Crup, conocido también como laringitis, laringotraqueitis 0 laringotraqueobronquitis, es una enfermedad respiratoria autolimitada, benigna y de etiología viral, principalmente por el virus Parainfluenza tipo 1(1). Esta enfermedad es la causa más frecuente de obstrucción aguda de la vía aérea superior en niños con edades entre los seis meses y los tres años, con una máxima incidencia a los dos años. Además, presenta una asociación estacional, con mayor prevalencia en otoño e invierno $(2,3)$.

Se divide en dos subtipos; crup recurrente y crup espasmódico. Esta patología se manifiesta clínicamente por presentar estridor inspiratorio, tos perruna y disfonía, secundarios a una inflamación en laringe y área subglótica por su patógeno ${ }^{1}$. La tos perruna tiene una duración de menos de 48 horas desde el inicio de sus síntomas, y en menos del cinco por ciento de los casos persiste hasta una semana $(4,5,6)$.

La incidencia anual es del tres por ciento en niños, pero menos del cinco por ciento de los casos requiere hospitalización $(5,7,8)$.

El objetivo de este artículo es presentar una clasificación práctica del crup según el grado 
de severidad del cuadro clínico, que permita un abordaje inicial en forma rápida y práctica en un primer nivel de atención, y evite el uso inadecuado de tratamientos farmacológicos.

\section{Metodología}

Para elaborar la siguiente revisión, se seleccionó un total de 17 referencias bibliográficas, tanto en inglés como en español, consultadas de las bases de datos de PubMed, Clinical key, Cochrane y UpToDate. Como filtro para la búsqueda, se toma en cuenta principalmente los artículos comprendidos entre los años 2015 hasta el 2019. Se elige los artículos actualizados con mayor relevancia en el tema a desarrollar, principalmente aquellos basados en la presentación clínica, abordaje, diagnóstico, manejo inicial y criterios de hospitalización. Al centrarse el artículo en el abordaje de crup en las edades de mayor frecuencia de presentación, se excluye aquellos artículos que abordan la patología en adolescentes y adultos.

\section{Etiología}

La etiología del crup es principalmente viral, el $75 \%$ de los casos son causados por el virus parainfluenza tipo 1 , con mayor predisposición en hombres, con una proporción de 1,5:1 en comparación con las mujeres $(1,2,3)$. Otros agentes etiológicos conocidos son el virus sincitial respiratorio, el adenovirus, el virus parainfluenza tipo 2 y 3 , el virus de sarampión, el virus influenza $A$ y $\mathrm{B}$, el coronavirus. En raras ocasiones la etiología puede ser bacteriana, causada por agentes como Haemophilus influenzae tipo b, Mycoplasma pneumoniae, Staphylococcus aureus, entre otros $(2,4,6)$. La incidencia del crup causado por Corynebacterium difteriae ha disminuido gracias a la aplicación de la vacuna contra la difteria ${ }^{2}$.

\section{Factores de riesgo}

Uno de los principales factores de riesgo identificados, es el antecedente familiar, por lo que un niño, cuyos padres presentaron crup durante la infancia, tiene un riesgo de 3,2 mayor de presentar crup, que aquel niño que no curse con dicho antecedente. Quienes tienen antecedentes familiares, presentan además una mayor probabilidad (aproximadamente 4,1), de cursar con crup recurrente, en comparación con aquellos niños sin antecedentes familiares $(2,6)$. Además, no se ha evidenciado el fumado pasivo como factor de riesgo para presentar dicha enfermedad (9).

\section{Fisiopatología}

Se ha demostrado la transmisión directa del virus de persona a persona e infecta inicialmente la mucosa nasal y faringe, posteriormente, coloniza el epitelio de la laringe y tráquea provocando eritema, edema y exudados fibrinosos que disminuyen el diámetro de la vía aérea $(2,9)$.

Esta hiperreactividad en la vía aérea, se debe a estímulos inespecíficos, como el reflujo gastroesofágico, la atopia, el estrés, y principalmente infecciones virales (10).

La zona más afectada es el área subglótica, que corresponde a la región bajo las cuerdas vocales, compuesta por el cartílago cricoides, que, por su anatomía, al ser un anillo cartilaginoso completo, no permite la expansión de su diámetro, alcanzando un diámetro de tan solo uno a dos milímetros en el crup, lo que aumenta la resistencia al flujo aéreo y provoca las complicaciones severas $(8,9)$.

Tanto en el crup recurrente como en el espasmódico, es posible encontrar edema no inflamatorio en el epitelio de la tráquea, lo que sugiere otras etiologías más allá de la viral, como reflujo gastroesofágico, esofagitis eosinofílica o candidiasis esofágica o antecedente de intubación reciente (9).

Existe mayor predisposición a padecer de crup 
a los dos años, probablemente debido a las diferencias anatómicas existentes en la vía aérea a esta edad, como la presencia de una glotis más alta, tejidos submucosos laxos y un espacio subglótico de menor tamaño².

\section{Presentación clínica}

Clínicamente, se caracteriza por presentar signos de dificultad respiratoria (aleteo nasal, retracciones, y en raras ocasiones, cianosis peribucal), asociados a una tos perruna, disfonía y estridor inspiratorio $(3,5)$. La tos característica se conoce como "tos perruna", ya que es disfónica, seca y metálica. Usualmente el cuadro resuelve por completo a las 48 horas, pero podría persistir hasta por una semana $(2,6)$.

Existe una fase prodrómica con síntomas de rinorrea hialina, coriza y congestión nasal que se presenta de 12 a 48 horas antes de la aparición de la tos (9). Solo algunos niños presentan fiebre, por lo que su presencia no es indispensable para el diagnóstico (3). Entre los signos clínicos más frecuentes destacan la bradipnea, estridor laríngeo, retracciones supraesternales y se ausculta un murmullo vesicular fisiológico normal o disminuido $(2,10)$.

Existen dos subtipos de presentación clínica, que se caracterizan de la siguiente forma $(5,6)$ :

- Crup recurrente, el cual es una recurrencia de la enfermedad en tres ocasiones distintas, es usualmente febril con síntomas persistentes.

- Crup espasmódico, se caracteriza por síntomas abruptos, de predominio nocturno, de corta duración, sin anormalidades anatómicas y con recurrencia de episodios sin antecedente de síntomas previos de vía aérea superior o fiebre.

\section{Diagnóstico}

El diagnóstico se basa en la presencia de los hallazgos clínicos característicos, y estos a su vez se utilizan para clasificar la patología según la severidad de la obstrucción $(1,6,11)$ :
-Crup leve: presenta tos perruna, estridor en actividad física y puede o no presentar leve dificultad respiratoria.

-Crup moderado: cursa con estridor en reposo, taquipnea, moderado trabajo respiratorio, agitación y dificultad para hablar o alimentarse.

-Crup severo: presenta estridor en reposo, dificultad para hablar o alimentarse y disminución del nivel de consciencia.

-Crup con inminente fallo respiratorio: se caracteriza por cianosis, bradipnea, dificultad respiratoria, con o sin estridor disminuido y disminución del nivel de conciencia.

\section{Estudios complementarios}

Los estudios complementarios se solicitan únicamente ante una clínica atípica, para descartar otros diagnósticos posibles o en caso de falla terapéutica (6). Entre los estudios de imagen, puede ser útil la radiografía anteroposterior cervical, que puede mostrar el signo "del arco gótico" o "del reloj de arena" o "del campanario", que se caracteriza por sobredistensión hipofaríngea con estrechez paradójica de la porción subglótica $(2,10)$. La laringotraqueobroncoscopia se realiza cuando se sospecha de aspiración de cuerpo extraño en la vía aérea o de traqueítis bacteriana (6).

Otros estudios complementarios, de baja utilidad diagnóstica, como el aspirado nasofaríngeo, se pueden utilizar para determinar la etiología exacta, así como serologías de virus influenza y virus sincitial respiratorio (3). Los gases arteriales se solicitan ante el inminente fallo respiratorio, como un criterio asociado a la clínica, que asiste en la decisión de utilizar terapias con oxígeno más invasivas (10).

\section{Clasificación del grado de severidad}

Para la clasificación del grado de severidad, se utiliza la escala de Westley, que establece una puntuación de 0 a 17 entre los siguientes factores: estridor, tiraje, ventilación, cianosis y 
nivel de conciencia. La puntuación se asigna de la siguiente manera: $(2,3,6)$

- Estridor inspiratorio: 0 (ausente), 1 (en reposo, audible con estetoscopio), 2 (en reposo audible sin estetoscopio).

- Tiraje: 0 (ausente), 1 (leve), 2 (moderado), 3 (grave).

- Murmullo vesicular: 0 (normal), 1 (disminuido), 2 (muy disminuido).

- Cianosis: 0 (ausente), 4 (con la agitación), 5 (en reposo).

- Nivel de conciencia: 0 (normal), 5 (alterado).

Una puntuación igual o mayor a dos indica crup leve, entre tres a cinco puntos cursa con crup moderado, entre seis a once puntos, crup severo y mayor $o$ igual a doce puntos equivale a un crup con inminente fallo respiratorio $(3,5)$.

\section{Criterios de ingreso hospitalario}

Al ser una enfermedad autolimitada, menos del cinco por ciento de la población requiere internamiento y de éstos, solo de uno a tres por cierto requerirán intubación (5). A continuación, se enumeran los criterios de ingreso hospitalario: $(2,10)$

- Lactante menor de seis meses.

- Patología subyacente de vía aérea superior.

- Signos de hipoxia: alteración del sensorio o estado general, palidez, cianosis.

- Estridor en reposo progresivo, tras tratamiento con esteroides y adrenalina en un periodo de observación de cuatro horas.

- Laringotraqueítis grave.

- Sospecha de epiglotitis.

- Antecedente de episodio grave.

- Consulta recurrente en urgencias por la misma causa.

- Diagnóstico incierto.

- Imposibilidad para dar seguimiento ambulatorio por padres inadecuados.

- Dificultad de acceso a la atención sanitaria.

\section{Diagnósticos diferenciales}

Considerar otros diagnósticos diferenciales en caso de: síntomas en niños menores de seis meses o mayores de seis años, presencia de tos persistente de más de 10 días, estridor de más de cuatro días de duración, antecedente de intubación prolongada o intubación no electiva en los últimos seis meses, sialorrea, aspecto tóxico, hemangioma cutáneo, cianosis, antecedente de crup recurrente con un segundo episodio en los últimos 30 días o en tercer episodio en los últimos 12 meses o falla terapéutica (11). Además, se debe descartar la presencia de crup de origen bacteriano en todo aquel niño que no responda al tratamiento (3).

Entre los diagnósticos diferenciales más frecuentes se encuentran los siguientes:

- Traqueítis bacteriana: causada por infección primaria de origen bacteriano, siendo el Staphylococcus aureus el principal agente etiológico causal, cursa con síntomas similares al crup, sin embargo, presenta fiebre más alta y una mayor incidencia en niños de edad escolar. También, puede presentarse traqueítis bacteriana secundaria, como complicación de un cuadro de infección viral $(1,6)$.

- Epiglotitis: enfermedad obstructiva de la vía aérea superior, en niños entre los dos a siete años, es causada por Haemophilus influenzae tipo B. Su clínica se caracteriza por fiebre alta, distrés respiratorio agudo con aleteo nasal, sialorrea constante y disfagia; usualmente, no presenta tos ni estridor. En la radiografía cervical lateral, se observa el signo del pulgar $(6,9)$. Su incidencia ha disminuido en un $80-90 \%$ en los últimos años, con la inclusión en el esquema de vacunación universal, de la vacuna contra el Haemophilus influenzae tipo $b(2)$.

- Aspiración de cuerpo extraño en vía aérea: obstrucción de vía respiratoria superior de inicio 
abrupto. Los síntomas varían de acuerdo con el sito de ubicación del objeto en vía aérea, si el objeto se aloja en laringe, puede presentar ronquera y estridor, mientras que, si está localizado en la región superior del esófago, presenta tos seca y estridor. A diferencia del crup, no presenta fiebre y en la radiografía de tórax o cervical, se puede observar un cuerpo extraño de aspecto radiopaco (6).

- Absceso y celulitis retrofaríngea: causado por diseminación hematógena de una infección primaria en otro sitio o secundario a trauma. Se presenta principalmente en niños de dos a cuatro años, se caracterizada por presentar fiebre y estridor, pero a diferencia del crup cursa con balbuceo, rigidez nucal, dolor faríngeo intenso, masa en el cuello, y no presenta tos (6). Para su diagnóstico es necesario realizar una tomografía axial computarizada $(1,2)$.

- Laringomalacia: malformación congénita que provoca obstrucción por colapso parcial de la vía aérea durante la inspiración, por debilidad muscular, provocando estridor y dificultad respiratoria, se presenta principalmente en niños de cuatro a ocho meses de edad (6).

- Hipocalcemia: se presenta como estridor por laringoespasmo asociado a deficiencia de vitamina D y complicaciones cardíacas como arritmias o disfunción ventricular izquierda. Se distingue del crup por no presentar síntomas respiratorios y se encuentra fuera del rango de edad típico (menores de seis meses y mayores de seis años) (12).

\section{Abordaje inicial}

Como medidas iniciales, se debe propiciar la disminución de la ansiedad del paciente manteniendo un ambiente tranquilo, en una posición cómoda, por ejemplo, sentado en los regazos de los padres $(4,7)$.

Sin excepción alguna, se debe garantizar la permeabilidad de la vía aérea, su adecuada oxigenación y ventilación utilizando las medidas terapéuticas necesarias, según sea el caso, con oxigenoterapia con nasocánula o mascarilla, a 2 a $3 \mathrm{~L} / \mathrm{min}$. No existe evidencia que demuestre el beneficio de la humidificación del oxígeno para el aclaramiento de las secreciones, por lo que no se recomienda su uso, incluso existe el riesgo de aumentar el broncoespasmo en caso de bronquitis (10).

Una vez asegurada la vía aérea, se iniciará el manejo terapéutico según el nivel de severidad de la crisis, de acuerdo con la puntuación obtenida en la escala de Westley, como se observa en la tabla $1(2,3,6,10)$.

\section{Terapia con glucocorticoides}

Se ha demostrado que los glucocorticoides son efectivos en el tratamiento de crup de todos los niveles de severidad. Una revisión Cochrane los asocia a una mejoría clínica, descrita como mejoría en las puntuaciones de Westley a las dos, seis, doce y veinticuatro horas (4). Disminuyen la estancia hospitalaria, reducen la necesidad de tratamiento con adrenalina, la necesidad de intubación y trasladados a UCl (10). Además, disminuyen la duración de la estancia en el servicio de emergencias o en el hospital y reducen las visitas de retorno o ingresos al hospital (13). El mecanismo de acción de los glucocorticoides consiste en contrarrestar los síntomas agudos de inflamación al inhibir la dilatación vascular, la formación de edema y la migración de leucocitos, y alivian la dificultad respiratoria debido a la inflamación de la laringe (14). La dexametasona es el agente glucocorticoide más ampliamente estudiado, es económico, fácil de administrar, tiene mayor potencia y duración de acción mayor comparado con otros agentes, presenta un inicio de acción de dos a tres horas y una vida media de 36 a 72 horas (10). La dosis óptima de dexametasona en crup es incierta, varía desde

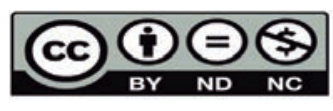


0.15 a $0.6 \mathrm{mg} / \mathrm{kg}$ y todas las dosis han demostrado ser efectivas. La dosis máxima varía de $10-20 \mathrm{mg}$ (16 mg). Para crup leve, moderado o severo se sugiere una dosis única de $0.6 \mathrm{mg} / \mathrm{kg}$ (máximo $16 \mathrm{mg}$ ), sin embargo, datos limitados sugieren que dosis más bajas $(0.15 \mathrm{mg} / \mathrm{kg}$ a $0.4 \mathrm{mg} / \mathrm{kg})$ son igualmente efectivas en crup leve, no obstante, una dosis más alta podría ser beneficiosa en enfermedad grave $(4,13)$.

Se puede administrar por vía intravenosa (IV), intramuscular (IM) u oral (VO), se debe preferir la vía menos invasiva posible, no hay diferencias clínicamente significativas entre dexametasona administrada por vía intravenosa o intramuscular, comparada con la vía oral. Mientras que la dexametasona nebulizada es menos efectiva que la oral (13).

Otra alternativa de tratamiento para el crup leve es usar prednisona o prednisolona, derivados sintéticos de glucocorticoides con efecto promedio de larga duración. La prednisona es el metabolito inactivo, es transformada en el hígado, por la enzima 11ß-hidroxiesteroide deshidrogenasa, en su forma biológicamente activa la prednisolona lo que retrasa es el inicio de la acción aproximadamente una hora. Además, la farmacocinética de prednisona y prednisolona es no lineal, ya que tienen unión variable a proteínas, por lo que los niveles plasmáticos no son predecibles fácilmente (14), se utiliza a dosis de $1 \mathrm{mg} / \mathrm{kg} / \mathrm{día}$ durante 3 días (10). La prednisolona puede administrarse por vía rectal, lo que representa una ventaja en pacientes con dificultades para tragar o que presentan vómitos o intolerancia a la vía oral (14).

La budesonida (inhalada) nebulizada es otra alternativa para quienes no toleran vía oral o carecen de acceso intravenoso (13). Estudios demuestran que la budesonida nebulizada es efectiva en el tratamiento de crup moderado y es útil como tratamiento coadyuvante en crup grave. Se administra a dosis de $2 \mathrm{mg}$, independientemente del peso y la edad. Alcanza una rápida disminución de la inflamación laríngea y mínimos o nulos efectos sistémicos. Ejerce su efecto al disminuir la permeabilidad vascular inducida por la bradicinina, con lo que se reduce el edema de la mucosa y, al estabilizar la membrana lisosómica, disminuye la reacción inflamatoria (10).

Los efectos secundarios asociados al tratamiento con glucocorticoides a corto plazo en su mayoría no son graves e incluyen hiperglicemia y cambios de comportamiento (angustia, hiperactividad, vómitos); el principal riesgo reportado es el potencial de infección viral progresiva o infección bacteriana secundaria (neumonía, otitis media aguda), pero estos efectos solo se han informado en el caso de tratamiento con glucocorticoides por varios días, o que recibieron dexametasona nebulizada y tenían neutropenia. No hay eventos adversos reportados asociados al uso de una dosis única de corticosteroides ni VO, IM o IV para el manejo de crup $(4,7,13)$.

No existen estudios comparativos de terapia en dosis única versus múltiples dosis, sin embargo, el efecto antinflamatorio de la dexametasona se mantiene por dos a cuatro días y el cuadro clínico, por lo general, se resuelve en 72 horas, por lo que resulta innecesario administrar dosis suplementarias. Se ha realizado estudios que evalúan la aplicación de dexametasona a distintas dosis, estos sugieren que la dosis convencional de $0,6 \mathrm{mg} / \mathrm{kg}$ es igual de efectiva que la dosis a $0,15 \mathrm{mg} / \mathrm{kg}$, pero los cuadros de mayor severidad se ven más favorecidos por terapias a altas dosis (7).

Se ha demostrado en estudios recientes que no hay diferencias clínicas significativa entre el uso de budesonida nebulizada comparada con dexametasona por IM, en ambos casos existe mejoría clínica, por lo que ambas terapias se recomiendan $(7,10)$. Al comparar la dexametasona IM versus betametasona VO, 
se demostró que ambas muestran mejoría en la escala de Westley a las cuatro horas, por lo que ambas vías de administración son válidas, sin embargo, se prefiere la administración vía oral, a menos que exista intolerancia por esta vía o el paciente se encuentre en estado de gravedad. Al comparar el uso de prednisolona 2 $\mathrm{mg} / \mathrm{kg} \mathrm{VO}$ versus dexametasona $0,15 \mathrm{mg} / \mathrm{kg} \mathrm{VO}$ se demostró que ambas son igual de eficaces cuando son administradas por primera vez en un paciente con crup, sin embargo, re consultan más frecuentemente quienes reciben prednisolona, probablemente por su menor tiempo de vida media $(7,13)$.

\section{Terapia con adrenalina nebulizada}

La adrenalina nebulizada está indicada en crup de moderado a severo, donde ha demostrado disminuir la necesidad de intubación o traqueotomía en comparación a placebo y existe mejoría del puntaje clínico a los 30 minutos (4).

Actúa generando vasoconstricción de las arteriolas precapilares mediante estimulación de alfa receptores, disminuyendo la presión hidrostática y, por tanto, el edema de la mucosa laríngea, aliviando la obstrucción de las vías aéreas y propiciando una mejora clínica considerable a corto plazo, sin alterar la historia natural de la enfermedad $(10,13)$. Su efecto es rápido, observándose mejoría dentro de los primeros 10 minutos, posteriores a la administración del medicamento, y el efecto clínico se mantiene durante al menos una hora; desaparece completamente después de dos horas. Se recomienda no utilizarla por horario, sino según respuesta clínica (15).

La nebulización simple (más utilizada en la clínica) o el uso de presión positiva intermitente con adrenalina son igualmente efectivos. Raramente se han informado efectos cardíacos adversos (los más frecuentes son taquicardia y palidez, se han reportado arritmias e isquemia miocárdica), sin embargo, son efectos clínicos temporales (menos de dos horas). Se ha reportado un "fenómeno de rebote", en el que los síntomas empeoran o reaparecen a medida que desaparecen los efectos de la epinefrina. Por lo tanto, para indicar un alta hospitalaria segura posterior a la administración de epinefrina nebulizada, se debe observar al paciente en el servicio de urgencias o en el hospital durante al menos tres a cuatro horas para asegurarse de que los síntomas no vuelvan a aparecer. El empeoramiento tras el efecto de la adrenalina se evita con la administración simultánea de corticoides $(4,10,13)$.

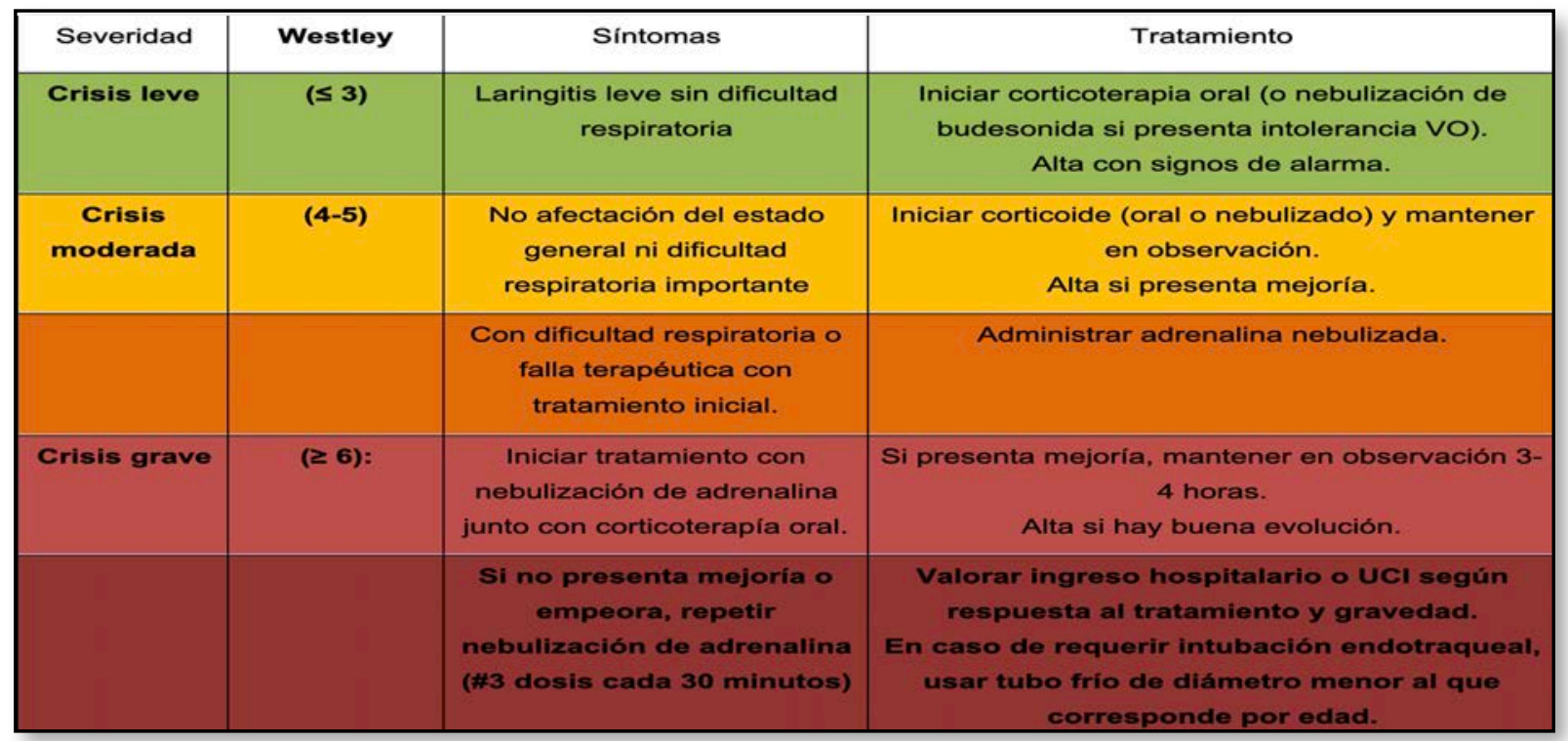

Cuadro elaborado por Natalia Salazar Campos, Nathalia A. Sandi Ovares, Carolina Mejía Arens. Basado en el articulo publicado por Ventosa P \& Luaces C (10) 


\section{Otras terapias}

No se indica de rutina el uso de antibióticos en crup típico, ya que la mayoría de los casos son de origen viral y menos de 1:1000 son de origen bacteriano. Se recomienda consultar a otorrinolaringología para valoración de la vía aérea, si los síntomas son persistentemente severos a pesar del tratamiento, también en caso de episodios recurrentes y aquellos fuera del rango de edad habitual (4).

No existen estudios que validen la eficacia del uso deanalgésicos, sedantes, antipiréticos, antitusivos, descongestionantes, broncodilatadores $\beta 2$ de acción corta o antiinflamatorios no esteroidales, por lo tanto, se recomienda evitarlos (10).

\section{Criterios de egreso hospitalario}

Se puede valorar el egreso hospitalario en pacientes que hayan recibido tratamiento y que cumplan los siguientes criterios: no presentar estridor en reposo, tolerancia de la vía oral a líquidos, habilidad para hablar, más de dos horas desde la última dosis de epinefrina, saturación de oxígeno mayor al $95 \%$, buen estado general sin cianosis ni dificultad respiratoria y con capacidad de reconsultar al hospital en caso de presentar signos de alarma, como estridor inspiratorio en reposo, tiraje, murmullo vesicular disminuido, cianosis en reposo y/o nivel de conciencia alterado. Se debe educar a los padres de familia sobre la importancia de comprender estos signos y síntomas que los alerten para acudir de nuevo a ser evaluados $(10,11)$.

\section{Conclusiones}

Los principales aspectos del abordaje inicial del crup, en medicina de atención primaria incluyen:

- El diagnóstico basado en la tríada clínica característica de tos perruna, disfonía y estridor inspiratorio.

- La clasificación de la severidad de la obstrucción, según la escala de Westley, según los hallazgos clínicos característicos, en crup leve, moderado, severo o con inminente fallo respiratorio.

- Se debe educar a los padres de familia sobre la importancia de los signos de alarma, y motivos para reconsultar si la evolución del cuadro no es la esperada.

- Es importante tener los distintos diagnósticos diferenciales en cuenta, de esta manera se pueden evitar desenlaces no deseados. Los diagnósticos diferenciales más importantes a tomar en cuenta son la traqueítis bacteriana, epiglotitis, cuerpo extraño en la vía aérea, Laringomalacia, absceso o celulitis retrofaríngeo.

- El manejo terapéutico se dirige según el nivel de severidad de la crisis:

En crup leve, se recomienda mantener al paciente respirando a aire ambiente, administrar dosis única de 0,6 $\mathrm{mg} / \mathrm{Kg}$ de dexametasona, IV, IM o VO. Como alternativa, igualmente eficaz, se puede utilizar prednisolona, oral, a dosis $1 \mathrm{mg} / \mathrm{Kg} /$ día cada $24 \mathrm{~h}$, por 3 días.

- En crup moderado, se debe administrar una dosis única de $0,6 \mathrm{mg} / \mathrm{Kg}$ de dexametasona, IV, IM o VO, seguida de adrenalina racémica a 0.05 $\mathrm{mL} / \mathrm{kg} /$ dosis (máximo $0.5 \mathrm{~mL}$ ) al $2.25 \%$ diluida a 3 $\mathrm{mL}$ de volumen total con solución salina o $5 \mathrm{~mL}$ de L-epinefrina a $0.5 \mathrm{~mL} / \mathrm{kg} / \mathrm{dosis}$ en dilución 1:1000, ambas dosis son estándar y se pueden usar en todos los pacientes independientemente de su edad y peso, durante 15 minutos. La mejoría se produce en 10-30 minutos y dura 1-2 horas, a partir de las cuales se produce el "fenómeno de rebote", en el que los síntomas empeoran o reaparecen a medida que desaparecen los efectos de la epinefrina, por lo que nunca se debe administrar adrenalina sin administración simultánea de corticoides. Se mantendrá en observación por al menos 3-4 horas tras la administración.

- En crup severo, se debe trasladar al paciente a un centro hospitalario de tercer nivel. Previo al 
traslado estabilizar administrando dexametasona a $0,6 \mathrm{mg} / \mathrm{kg}$ y adrenalina nebulizada a la misma dosis que en la moderada. Si es necesario se pueden repetir las dosis de adrenalina cada 150 20 minutos, hasta tres dosis. Otra terapia efectiva es el uso de gas heliox, que se administra en forma continua ante una respuesta parcial a adrenalina, siempre en conjunto con esteroides.

- El crup con inminente fallo respiratorio, con nivel de conciencia alterado o cianosis, son indicación de tratamiento inicial como se indica anteriormente $y$ traslado de inmediato en ambulancia con médico tratante a un tercer nivel.

- Otros factores de riesgo para considerar un traslado a urgencias son: necesidad de una segunda dosis de adrenalina, antecedente de un episodio moderado-grave, edad menor de 6 meses, presencia de comorbilidades tales como cardiopatía, displasia broncopulmonar, historia previa de obstrucción o malformación estructural de la vía aérea, enfermedad neuromuscular o problemática social o familiar que impidan reconsultar en caso de empeoramiento de los síntomas.

- Indicar el alta al domicilio, en el caso de crup leve a moderado, el paciente debe cumplir con todos los siguientes criterios: no presentar estridor en reposo, tolerancia de la vía oral a líquidos, habilidad para hablar, más de dos horas desde la última dosis de epinefrina, saturación de oxígeno mayor al 95\%, buen estado general sin cianosis ni dificultad reåspiratoria y con capacidad de re consultar al hospital en caso de presentar signos de alarma. Si ha necesitado adrenalina nebulizada se aconseja esperar 3-4 horas y se recomienda un nuevo control en consulta externa a las 24 horas.

\section{Bibliografía}

(1) Loftis LL. (2020). Emergency evaluation of acute upper airway obstruction in children. En: UpToDate [en línea] [consultado el 20/2/2020]. Recuperado de https://www.uptodate.com/ contents/emergency-evaluation-of-acute-upperairway-obstruction-in-children

(2) Temprano M, Hinojl TI. (2017). Laringitis, crup y estridor. Pediatría Integral. XXI(7):458-464.

(3) Sizar O, Carr B. Croup. Croup. [Actualizado 2019 Nov 7]. In: StatPearls [Internet]. Treasure Island (FL): StatPearls Publishing; 2020. Recuperado de: https://www.ncbi.nlm.nih.gov/ books/NBK431070/

(4) Ortiz O, et al. (2017). Canadian Paediatric Society: Practice Point: Acute Management of
Croup in the Emergency Department. Paediatrics \& Child Health.166-169.

(5)Johnson DW. (2016). Croup. Am Fam Physician. 94(6): 476-478.

(6)Clinical overview. Croup. [Actualizado 2019 oct 22]. Elsevier Point of Care. Copyright Elsevier BV. Clinicalkey. Recuperado de https://wwwclinicalkey-com.ezproxy.sibdi.ucr.ac.cr/\#!/content/ clinical_overview/67-s2.0-e31a005b-06b6-4041$8 a 66-9 d 4 d b 9 d 0 f 381$ ?scrollTo $=\% 23$ monitoringheading-40

(7)Gates A, Gates M, Vandermeer B, Johnson C, Hartling L, Johnson DW, Klassen TP. (2018). Glucocorticoids for croup in children. Cochrane Database Syst Rev. 8:CD001955.

(8)Fuentes C, Peña R, Vinet M, Zenteno D. (2014). Croup, tratamiento actual. Neumol Pediatr. 9 (2): 55-58.

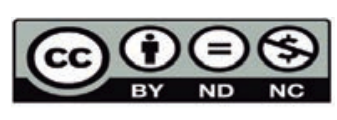


(9) Wood CR. (2020). Croup: Clinical features, evaluation, and diagnosis. En: Uptodate [en línea] [consultado el 20/2/2020]. Recuperado de https://www.uptodate.com/contents/croup-clinicalfeatures-evaluation-and-diagnosis

10) Ventosa P, Luaces C. (2019). Diagnóstico y tratamiento de la laringitis en Urgencias. Sociedad Española de Urgencias de Pediatría (SEUP), 3a Ed. Recuperado de https://seup.org/pdf_public/ pub/protocolos/6_Laringitis.pdf

(11) Northern California Pediatric Hospital Medicine Consortium: Consensus Guidelines for Management of Croup. (2016). UCSF Benioff Children's Hospital website. Recuperado de https://www.ucsfbenioffchildrens.org/pdf/croup_ full_guideline.pdf

(12) Gardner A, Ruch A. (2018). Not all stridor is croup. Pediatr Emer Care. 00: 1-4.

(13) Wood CR. (2020). Management of Croup. En Uptodate, [en línea] [consultado el 20/2/2020]. Recuperado de https://www-uptodate-com. ezproxy.sibdi.ucr.ac.cr/contents/managementof-croup? search =croup \&source=search result \&selected Title $=1 \sim 74$ \& usage type=default\&display_rank=1

(14) Eckhard Beubler Peter Dittrich. (2015). About the therapyoflaringotracheitis(Croup):Significance of Rectal Dosage Forms. Pharmacology. 95:300302.

(15) Kawaguchi A Joffe A. (2015). Evidence for clinicians: nebulized epinephrine for croup in children. Paediatr Child Health. 20(1):19-20.

(16) Bjornson C, Russell K, Vandermeer B, Klassen TP, Johnson DW. (2013). Nebulized epinephrine for croup in children. Cochrane Database Syst Rev. 10: CD006619.
(17) Moraa I, Sturman N, McGuire TM, van Driel ML. (2018). Heliox for croup in children. Cochrane Database Syst Rev. 10: CD006822. 